\title{
Spectrum of congenital heart disease detected echocardiographically in prenatal life
}

\author{
LINDSEY D ALLAN, DIANE C CRAWFORD, ROBERT HANDERSON, * \\ MICHAEL TYNAN \\ From the Department of Paediatric Cardiology, Guy's Hospital, and ${ }^{\star}$ the Cardiothoracic Institute, Brompton \\ Hospital, London
}

SUMMARY The spectrum of congenital heart disease seen in a series of 72 fetal anomalies detected echocardiographically differed from that seen in infancy. This reflects the selection of patients for referral for fetal echocardiography and the high rate of natural fetal loss that occurs when severe cardiac defects are present.

It was our impression, based on five years' experience of fetal echocardiography for the prenatal detection of congenital heart disease, that a higher proportion of the cases diagnosed in utero have had severe malformations than do cases presenting in infancy. ${ }^{12}$ Cardiac abnormalities seen at abortion and stillbirth are more severe than those diagnosed after birth. ${ }^{3-5}$ We have reviewed the spectrum of cardiac anomalies encountered in $\mathbf{7 2}$ fetuses with malformed hearts that were identified by echocardiography.

\section{Patients and methods}

Patients were referred for fetal echocardiography for the following reasons: a family history of congenital heart disease; exposure to a teratogen (such as lithium, phenytoin, or rubella) in early pregnancy; the detection of non-immune hydrops fetalis; fetal arrhythmia; or an extracardiac anomaly such as exomphalos, neural tube defects, or renal abnormalities. Others were referred because a possible cardiac anomaly was reported at obstetric ultrasonography - usually because of an increase in the size of the heart or a failure to identify four cardiac chambers.

Congenital heart diseases were classified in order of importance (Table 1). The dominant lesion in

Requests for reprints to Dr Lindsey D Allan, Department of Paediatric Cardiology, Guy's Hospital, St Thomas Street, London SE1 9RT.

Accepted for publication 12 August 1985 each heart was selected by a modification of the methods proposed by Fyler et $a l^{1}$ and Scott et al. ${ }^{2}$ The nomenclature used is that of Tynan et al. ${ }^{6}$ Hearts with more than one lesion were classified according to the more important lesion. Thus coarctation coexisting with a ventricular septal defect was classified as coarctation. In contrast,

Table 1 Classification of congenital heart disease by the dominant lesion in complex cases. (Diagnoses are listed in decreasing order of importance.)

Absent atrioventricular connection

Double inlet atrioventricular connection

Atrioventricular discordance with ventriculoarterial discordance (congenitally corrected transposition)

Hypoplastic left heart syndrome

Truncus arteriosus

Atrioventricular concordance with ventriculoarterial discordance (complete transposition)

Interrupted aortic arch

Atrioventricular septal defect

Double outlet ventricle

Coarctation of aorta

Absent pulmonary valve syndrome

Ebstein's anomaly

Pulmonary atresia

Tetralogy of Fallot

Pulmonary stenosis

Cor triatriatum

Total anomalous pulmonary venous connection

Aortopulmonary window

Hypertrophic obstructive cardiomyopathy

Aortic stenosis

Persistent ductus arteriosus

Pulmonary artery anomalies

Atrioventricular valve anomalies

Myocardial disease

Atrial isomerism

Peripheral pulmonary stenosis

Systemic arteriovenous fistula

Pulmonary arteriovenous fistula

Secundum atrial septal defect 
coarctation and absence of the left atrioventricular connection, that is right atrium connected to a dominant left ventricle and with a discordant ventriculoarterial connection was classified as absent left connection. Atrioventricular septal defect when it coexisted with double outlet right ventricle or pulmonary atresia was classified as atrioventricular septal defect. Conversely, in cases where a common atrioventricular valve was committed predominantly to one ventricle (the other ventricle being rudimentary and hypoplastic) the constellation was coded as double inlet ventricle. We considered Ebstein's anomaly to the more important lesion when it coexisted with pulmonary stenosis or atresia and have therefore placed it higher in the list than it appears in the series of Scott et $a l^{2}$ and Fyler et al. ${ }^{1}$ Only one diagnosis was recorded for each case. The classification will underestimate the total frequency of conditions such as pulmonary stenosis, coarctation, or ventricular septal defect because they appear at the bottom of the list, even though they are common components of complex disease. This must be taken into account when our data are compared with others in which this classification was not used.

In preparing our table of results (Table 2 ) we

Table 2 Percentage distribution of heart disease in three series

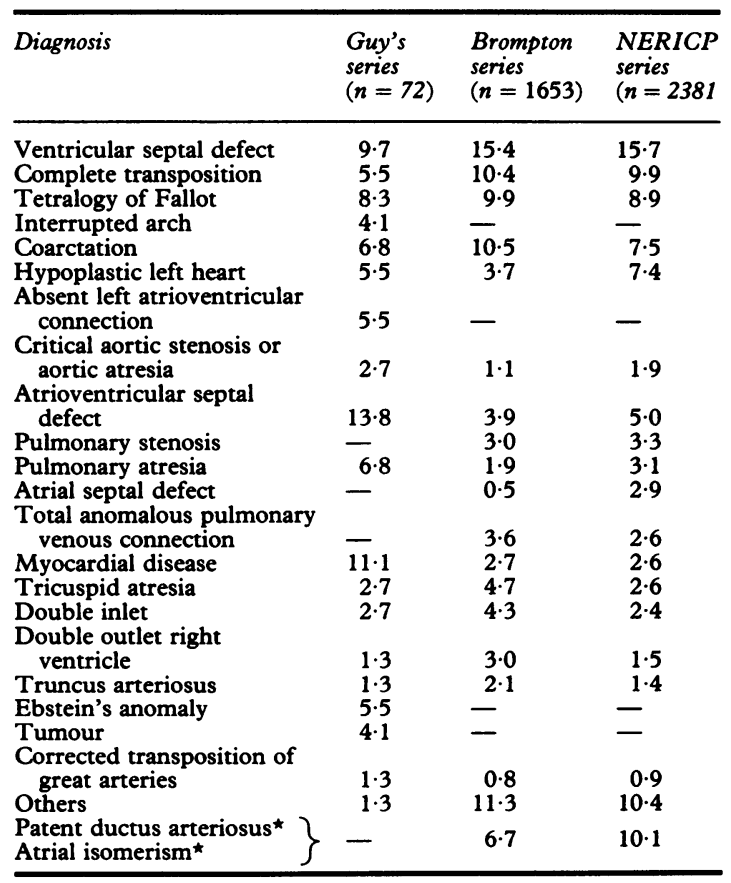

NERICP, New England Regional Infant Cardiac Program. $\star$ Excluded from Guy's series. made some changes to the previous studies of heart disease in infancy. ${ }^{2}$ We did not include persistent patency of the arterial duct (ductus arteriosis) because this is a normal readily identifiable fetal structure. Atrial isomerism, which was present in nine of our cases, was not a primary diagnosis in any, and has also been omitted from the list. Absent left connection with double outlet right ventricle has been added to the list. We defined hypoplastic left heart syndrome as the combination of obstruction at the mitral and aortic valves. Isolated mitral atresia was designated as absent left connection and isolated aortic atresia as aortic atresia. Ebstein's anomaly, interrupted aortic arch, and cardiac tumours have been added to the list.

In the first part of our analysis we compared prenatal diagnoses with those recognised in infancy by Fyler et $a l^{1}$ and Scott $e t a{ }^{2}{ }^{2}$ In the second part we compared the diagnoses in our series with a series of cases identified at abortion ${ }^{3}$ and in two stillbirth series. ${ }^{45}$ The abortion series was compared directly with our series because the abnormalities recognised could be coded in the same way. This was not possible for the stillbirth series. We therefore listed these cases according to the assigned diagnoses.

\section{Results}

A cardiac malformation was identified by fetal echocardiography in 72 fetuses. Sixty seven of these fetuses died. In all the malformation was confirmed at necropsy. There were 34 terminations of pregnancy, 13 intrauterine deaths, and 20 neonatal deaths. There are five survivors, three have not yet been delivered and in two the diagnosis was confirmed by postnatal echocardiography and catheterisation and at operation. Of these two, one had complete transposition (the combination of concordant atrioventricular and discordant ventriculoarterial connections) and one had aortic coarctation.

The diagnoses in the whole group were compared with the diagnoses of those presenting in the first year of life (Table 2). There are some obvious differences between the series. In our 72 cases there was a relative paucity of ventricular septal defects, pulmonary stenosis, atrial septal defect, and total anomalous pulmonary venous connection. There was also an excess of absent left atrioventricular connection, interrupted aortic arch, pulmonary atresia with intact spetum, atrioventricular septal defect, myocardial disease, Ebstein's anomaly, and cardiac tumour in our series.

Table 3 compares our series with a large stillbirth series ${ }^{4}$ and a more recent stillbirth study. ${ }^{5}$ There were more atrial and ventricular septal defects in the 
Table 3 Comparison of frequency of congenital heart disease in fetal series and two stillbirth series

\begin{tabular}{|c|c|c|c|}
\hline Diagnosis & $\begin{array}{l}\text { Guy's } \\
\text { series } \\
(n=72) \\
(\%)\end{array}$ & $\begin{array}{l}\text { Combined } \\
\text { stillbirth } \\
\text { series } \\
(n=265)^{4} \\
(\%)\end{array}$ & $\begin{array}{l}\text { Stillbirth } \\
\text { series } \\
(n=81)^{5} \\
(\%)\end{array}$ \\
\hline $\begin{array}{l}\text { Ventricular septal defect } \\
\text { Complete transposition } \\
\text { Tetralogy of Fallot } \\
\text { Interrupted arch } \\
\text { Coarctation } \\
\text { Hypoplastic left heart } \\
\text { Absent left connection } \\
\text { Double inlet } \\
\text { Tricuspid atresia } \\
\text { Critical aortic stenosis } \\
\text { Atrioventricular septal } \\
\text { defect } \\
\text { Pulmonary atresia, } \\
\text { intact ventricular septum } \\
\text { Atrial septal defect } \\
\text { Tumour } \\
\text { Double outlet right } \\
\text { ventricle } \\
\text { Pulmonary stenosis } \\
\text { Myocardium disease } \\
\text { Truncus arteriosus } \\
\text { Ebstein's anomaly } \\
\text { Miscellaneous }\end{array}$ & 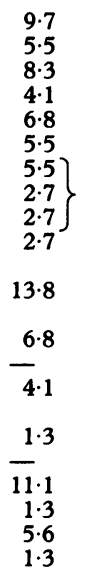 & $\begin{array}{r}34 \cdot 7 \\
9 \cdot 1 \\
8 \cdot 4 \\
9 \cdot 4 \\
3 \cdot 0 \\
6 \cdot 4 \\
0 \cdot 0 \\
6 \cdot 8 \\
1 \cdot 1 \\
10 \cdot 2 \\
\\
0 \cdot 4 \\
1 \cdot 1 \\
0 \cdot 0 \\
6 \cdot 0 \\
6 \cdot 4\end{array}$ & $\begin{array}{r}32 \cdot 1 \\
3 \cdot 7 \\
8 \cdot 6 \\
-3 \cdot 7 \\
7 \cdot 4 \\
2 \cdot 5 \\
1 \cdot 2 \\
1 \cdot 2 \\
6 \cdot 2 \\
7 \cdot 4 \\
3 \cdot 7 \\
7 \cdot 4 \\
- \\
3 \cdot 7 \\
11 \cdot 2\end{array}$ \\
\hline
\end{tabular}

two stillbirth series and an excess of cases of interrupted aortic arch, absent left or right atrioventricular connection, atrioventricular septal defect, myocardial disease, Ebstein's anomaly, and cardiac tumours in our series.

Table 4 compares our series and a study of cases obtained from spontaneous abortions. There are fewer cases of tetralogy of Fallot, tricuspid atresia,

Table 4 Comparison of frequency of congenital heart disease in fetal series and abortion series

\begin{tabular}{llc}
\hline Diagnosis & $\begin{array}{l}\text { Guy's } \\
\text { series } \\
(n=72) \\
(\%)\end{array}$ & $\begin{array}{l}\text { Abortion } \\
\text { material } \\
(\boldsymbol{n}=38) \\
(\%)\end{array}$ \\
\hline Ventricular septal defect & $9 \cdot 7$ & $10 \cdot 4$ \\
Complete transposition & $5 \cdot 5$ & $2 \cdot 7$ \\
Tetralogy of Fallot & $\mathbf{8} \cdot 3$ & $15 \cdot 6$ \\
Interrupted arch & $4 \cdot 1$ & $5 \cdot 3$ \\
Coarctation & $6 \cdot 8$ & $5 \cdot 3$ \\
Hypoplastic left heart & $5 \cdot 5$ & $2 \cdot 7$ \\
Absent left atrioventricular connection & $5 \cdot 5$ & $7 \cdot 9$ \\
Critical aortic stenosis & $2 \cdot 7$ & $2 \cdot 7$ \\
Atrioventricular septal defect & $13 \cdot 8$ & $10 \cdot 4$ \\
Pulmonary atresia, intact ventricular & & \\
septum & $6 \cdot 8$ & - \\
Total anomalous pulmonary venous & & $2 \cdot 7$ \\
connection & $-11 \cdot 1$ & - \\
Myocardial disease & $2 \cdot 7$ & $7 \cdot 9$ \\
Tricuspid atresia & $2 \cdot 7$ & - \\
Double inlet & $1 \cdot 3$ & $10 \cdot 4$ \\
Double outlet right ventricle & $1 \cdot 3$ & $2 \cdot 7$ \\
Truncus arteriosus & $5 \cdot 5$ & - \\
Ebstein's anomaly & $4 \cdot 1$ & $-5 \cdot 3$ \\
Tumour & $1 \cdot 3$ & $7 \cdot 9$ \\
Corrected transposition of great arteries & $1 \cdot 3$ & \\
Others & & \\
\hline
\end{tabular}

and double outlet right ventricle in our series. Pulmonary atresia with intact ventricular septum, myocardial disease, Ebstein's anomaly, and cardiac tumours were more common in our series. There was a notable similarity between the frequency of all septal defects and of left sided lesions in the two groups.

\section{Discussion}

Many of the differences between the series can be accounted for by the selection of patients for referral for fetal echocardiography. Few mothers who have had children with mild heart disease (for example, septal defects or pulmonary stenosis) are referred for examination. Whereas mothers who have had a child who died of major congenital heart disease are more likely to be referred.

Some defects are over-represented in our series as compared with all the other series. These are pulmonary atresia with intact septum, myocardial disease, Ebstein's anomaly, and cardiac tumours. In the fetus pulmonary atresia with intact septum and Ebstein's anomaly both produce gross cardiac enlargement that is readily recognisable at routine ultrasonography. It is perhaps surprising that these defects were less commonly recognised in the series of stillbirths and aborted fetuses, since of our nine cases with these two diagnoses, one resulted in spontaneous abortion and five in stillbirths. The high frequency of myocardial disease seen in our series is due to the selection of pregnancies where renal anomalies have been detected in the fetus. These cases have hypertrophic cardiomyopathy with echocardiographic evidence of obstruction to left ventricular outflow, such as midsystolic closure of the aortic valve and systolic anterior motion of the mitral valve. Hypertrophic cardiomyopathy has been reported in association with renal disease. ${ }^{7}$ Fetal cardiac tumours present with evidence of obstruction to cardiac output and intrauterine cardiac failure and two of our three cases died in utero. In one the pregnancy was terminated. This high incidence of fetal loss secondary to cardiac tumour may account for the rarity of this lesion after birth.

Atrioventricular septal defect was more common in our series than it was after delivery. This also can partly be accounted for by the high rate of fetal loss. Of 12 cases with this diagnosis only two were associated with chromosome anomalies. Six pregnancies were terminated, two cases died after birth, but four cases died in utero. This high rate of fetal loss was also found in the spontaneous abortion series, in which the frequency of atrioventricular septal defects resembled our results. ${ }^{3}$

The greatest disparity in all the comparisons is 
between the present series and the stillbirth series. This may be accounted for by differences in coding diagnosis or inaccuracy of diagnosis in the stillbirth series. If some of the ventricular septal defects reported in the stillbirth series were cases of tetralogy of Fallot or atrioventricular septal defect, the studies might become more similar. Because the abortion series and the two stillbirth series were reported by specialists in congenital heart disease, criteria for diagnosis and nomenclature are more likely to be consistent. Furthermore, they used the same coding system and thus differences between the series are likely to be real. The difficulties in comparing different series, however, emphasise the importance of an international, common nomenclature and method of classification of diagnosis in congenital heart disease.

In summary, there are major differences between the spectrum of congenital heart disease seen prenatally and postnatally. Complex defects are more common prenatally. This is partly accounted for by the selection of patients for referral for fetal echocardiography but also perhaps by the unexpectedly high rate of fetal wastage when such defects are severe. An accurate picture of the true prevalence of congenital heart disease requires a large prospective study of an unselected series of pregnancies. Cases will be missed unless all fetuses are studied by echocardiography and are followed up postnatally by paediatric cardiologists; when abortion occurs the fetus must be expertly examined. The current simplicity and accuracy of fetal echocardiography ${ }^{8}$ makes this by no means an impossible proposition.

Dr Allan, Dr Crawford, and Professor Anderson are supported by the British Heart Foundation, the latter in association with the Joseph Levy Foundation.

\section{References}

1 Fyler DC, Buckley LP, Hellenbrand WE, et al. Report of the New England Regional Infant cardiac program. Pediatrics 1980; 65: 375-461.

2 Scott DJ, Rigby ML, Miller GAH, Shinebourne EA. The presentation of symptomatic heart disease in infancy based on 10 years experience (1973-82). Implications for the provision of services. Br Heart $\mathcal{F} 1984$; 52: 248-57.

3 Gerlis LM. Cardiac malformations in spontaneous abortions. Int $\mathcal{F}$ Cardiol 1985; 7: 29-43.

4 Hoffman JIE, Christianson R. Congenital heart disease in a cohort of 19,502 births with long-term follow-up. Am 7 Cardiol 1978; 42: 641-7.

5 Samánek M, Goetzová J, Benešova D. Distribution of congenital heart malformations in an autopsied child population. Int $\mathcal{f}$ Cardiol 1985; 8: 235-48.

6 Tynan MJ, Becker AE, Macartney FJ, Quero-Jiménez M, Shinebourne EA, Anderson RH. Nomenclature and classification of congenital heart disease. Br Heart $\mathfrak{f}$ 1979; 41: 544-53.

7 Abbasi AS, Slaughter JC, Allen MW. Asymmetric septal hypertrophy in patients on long term hemodialysis. Chest 1978; 74: 548-51.

8 Allan LD, Crawford DC, Anderson RH, Tynan MJ. Echocardiographic and anatomical correlations in fetal congenital heart disease. Br Heart $\mathcal{f}$ 1984; 52: 542-8. 